\title{
Intensive vehicle traffic impacts morphology and endocrine stress response in a threatened amphibian
}

\author{
Hugo Cayuela, Ludivine Quay, Adeline Dumet, Jean-Paul Léna \\ Claude Miaud and Vincent Rivière
}

\begin{abstract}
Amphibians are considered to be the most threatened group of vertebrates. Among the multiple factors involved in their decline, habitat loss and alteration as a result of human activities is a major threat. At the individual level the effects of habitat alteration are potentially multiple, including a range of morphological and physiological responses. Analysing and understanding these responses is therefore a critical challenge for amphibian conservation. We examined the influence of intensive vehicle traffic (motorbikes and trucks on unpaved pathways) on the body size and condition and on the production of glucocorticoids (i.e. corticosterone) in the yellow-bellied toad Bombina variegata. In particular, we tested the hypothesis that intensive vehicle traffic has a negative influence on body size and body condition, and postulated that it also increases corticosterone production. Using morphometric data and saliva samples collected from four populations in France, we found that intensive vehicle traffic is associated with a decrease in body size and body condition in both males and females. Furthermore, our analysis revealed that corticosterone production was lower in both sexes in populations experiencing intensive vehicle traffic. We suggest that measures should be applied to reduce vehicle traffic intensity on unpaved pathways during toad breeding activity. This is critical for $B$. variegata, for which man-made ruts and residual puddles could mitigate the loss of natural habitats.
\end{abstract}

Keywords Amphibian, body condition, body size, Bombina variegata, corticosterone, vehicle traffic, yellow-bellied toad

Hugo Cayuela* (Corresponding author), Adeline Dumet and Jean-Paul Léna Laboratoire d'Ecologie des Hydrosystèmes Naturels et Anthropisés, UMR 5023 LEHNA, Campus de la Doua, 43 boulevard du 11 novembre 1918, 69100 Villeurbanne, France. E-mail hugo.cayuela@univ-lyon1.fr

Ludivine Quay Ligue pour la Protection des Oiseaux, La Motte-Servolex, France Claude Miaud Laboratoire d'Ecologie et de Biogéographie des Vertébrés, Montpellier, France

Vincent Rivière AGIR Ecologique, Atelier de Gestion, d'Ingénierie et de Restauration Ecologiques, Saint-Maximin la Sainte-Baume, France

*Also at: Ligue pour la Protection des Oiseaux, La Motte-Servolex, France

Received 19 April 2015. Revision requested 24 June 2015.

Accepted 26 June 2015. First published online 22 October 2015.

\section{Introduction}

mphibians are the most threatened group of verteA brates, with multiple causes implicated in their decline, including the emergence of new pathogens (Blaustein et al., 2012), biological invasions (Kats \& Ferrer, 2003), climate change (Carey \& Alexander, 2003) and habitat loss and alteration (e.g. as a result of intensive vehicle traffic; Cushman, 2006). At the individual level the consequences of habitat alteration are potentially multiple and may include a range of morphological (Todd \& Rothermel, 2006) and physiological responses (Narayan, 2013).

Reduced body size (a trend toward dwarfism) as a result of habitat alteration has been reported (e.g. Todd \& Rothermel, 2006), and may be a result of maternal effects (e.g. decrease in energy investment in breeding), ontogenic factors during the larval phase (e.g. changes in larval density or thermal condition) or life history traits (e.g. decreased survival after metamorphosis affecting age structure and size pattern). Furthermore, studies have shown that a decline in body condition may be caused by modifications of habitat structure and trophic productivity (Denoël \& Poncin, 2001; Janin et al., 2011). These changes in body size and condition may directly or indirectly cause a decrease in fitness (Altwegg \& Reyer, 2003).

Few studies have provided evidence that habitat alteration influences endocrine stress responses in amphibians (for a review see Narayan, 2013). Maintaining homeostasis (i.e. the stability of physiological systems that maintain life) through environmental changes depends on a set of mechanisms called allostasis (maintaining stability through change; McEwen \& Wingfield, 2003). In vertebrates the main allostasis mediators are glucocorticoid hormones (e.g. corticosterone), which are usually considered an indicator of endocrine stress response (Moore \& Jessop, 2003). These hormones play a critical role in blood glucose regulation but also perform a range of other functions, including effects on intermediary metabolism, immune function, behaviour, electrolyte balance, growth and reproduction (Hill et al., 2008).

Analysing and understanding how habitat alteration may shape morphological and physiological responses in amphibians is an important challenge for conservation strategies. We examined the influence of intensive vehicle traffic (motorbikes and trucks on unpaved pathways) on the body size and condition and the production of glucocorticoids (i.e. corticosterone) in the yellow-bellied toad Bombina 
variegata. Although this species is categorized as Least Concern on the IUCN Red List (Kuzmin et al., 2009; IUCN, 2015), populations have experienced significant decline in Western Europe during the 2oth century (Lescure et al., 2011). Several factors, such as habitat loss and changes in farming practices, have been proposed to explain this decline (Canessa et al., 2013). For nearly a century the increasing mechanization of forestry, agricultural and mining activities has contributed to landscape change and habitat availability. In particular, these activities create water bodies (e.g. ruts, residual puddles on unpaved pathways) in which B. variegata can reproduce (e.g. Cayuela et al., 2014). These semi-natural environments are mainly characterized by a low water volume with a high risk of drying up (Kopecky et al., 2010), and few competitors and predators (Barandun \& Reyer, 1998), and therefore they fulfil the biotic and abiotic conditions that prevail in natural water bodies used for breeding by B. variegata (Cayuela et al., 2011, 2013). Furthermore, they may compensate locally for the loss of natural habitats as a result of agricultural development and urbanization (Cayuela et al., 2015). However, the benefits provided by the availability of these substitute breeding sites could be balanced by costs such as intensive vehicle traffic on unpaved pathways, which may damage breeding and terrestrial habitats. Using data collected from four populations we tested the hypothesis that intensive vehicle traffic (motorbikes and heavy trucks) negatively influences both body size and body condition among yellow-bellied toads. We also postulated that such traffic could lead to an increase in corticosterone production.

\section{Methods}

\section{Field sampling}

The study was conducted in May 2014 in four populations (corresponding to distinct clusters of water bodies) in Savoie and Haute-Savoie, France (Fig. 1). We selected two populations that were exposed to intensive vehicle traffic (allterrain vehicles, including motorcycles and heavy trucks) at least once per day, and two control populations, which were not exposed to traffic. We assumed that the four populations were comparable, considering latitude and altitude (Table 1 ). In exposed populations (POP1 and POP2) the toads bred in ruts and shallow ponds in two stone quarries, which were continuously damaged by all-terrain vehicles and trucks. In control populations ( $\mathrm{POP}_{3}$ and $\mathrm{POP}_{4}$ ) breeding took place in ruts and shallow ponds in a wet meadow and in a stone quarry that had not been exploited since 1993; access for vehicles to these sites was limited. The four populations were sampled over a 2-day period; one exposed and one control population were sampled per day. Only sexually mature individuals were captured, and sex was identified on

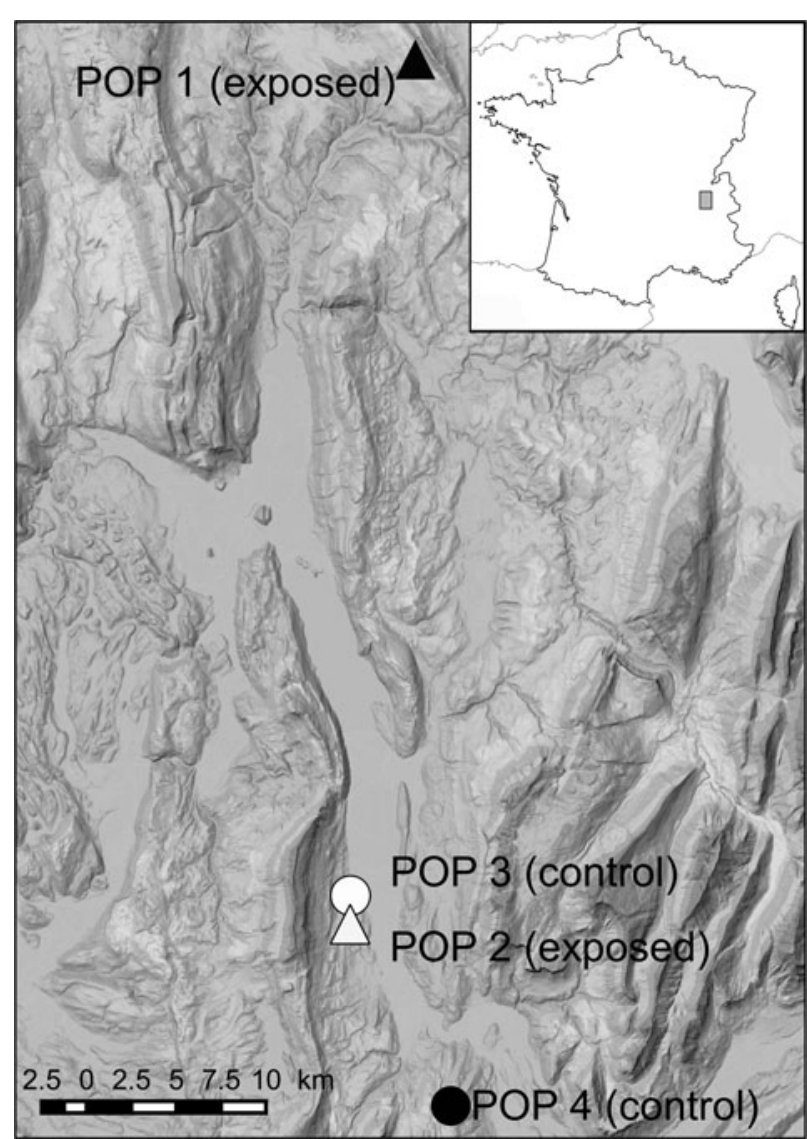

FIG. 1 Locations of two populations of yellow-bellied toads Bombina variegata exposed to intensive vehicle traffic, and two control populations, in Savoie and Haute-Savoie, France.

TABLE 1 Details of two populations of yellow-bellied toads Bombina variegata exposed to intensive vehicle traffic, and two control populations, in Savoie and Haute-Savoie, France, with population status, vehicle type, altitude and habitat type.

\begin{tabular}{|c|c|c|c|c|}
\hline Population & $\begin{array}{l}\text { Population } \\
\text { status }\end{array}$ & $\begin{array}{l}\text { Vehicle } \\
\text { type }\end{array}$ & $\begin{array}{l}\text { Altitude } \\
(\mathrm{m})\end{array}$ & $\begin{array}{l}\text { Habitat } \\
\text { type }\end{array}$ \\
\hline POP1 & Exposed & $\begin{array}{l}\text { Heavy } \\
\text { trucks, } \\
\text { motorbikes }\end{array}$ & 673 & $\begin{array}{l}\text { Active } \\
\text { quarry \& } \\
\text { motocross } \\
\text { circuit }\end{array}$ \\
\hline POP2 & Exposed & Motorbikes & 299 & $\begin{array}{l}\text { Motocross } \\
\text { circuit }\end{array}$ \\
\hline POP3 & Control & None & 294 & $\begin{array}{l}\text { Disused } \\
\text { quarry \& } \\
\text { meadows }\end{array}$ \\
\hline POP4 & Control & None & 571 & Meadows \\
\hline
\end{tabular}

the basis of stronger forearms and the presence of nuptial pads in males. Adults were captured at random in the daytime, by hand or using a dip net (Table 2). To measure corticosterone production, within 3 minutes of capture a dry cotton ball of known weight was inserted into the mouth for $30 \mathrm{~s}$ to collect saliva. As changes in corticosterone 
TABLE 2 Sample sizes (n) of male and female yellow-bellied toads in two populations exposed to intensive vehicle traffic (POP1 and POP2) and two control populations ( $\mathrm{POP}_{3}$ and $\mathrm{POP}_{4}$ ), with descriptive statistics for body size (snout-vent length), mass and baseline corticosterone concentrations in saliva.

\begin{tabular}{|c|c|c|c|}
\hline & Size $(\mathrm{mm})$ & Body mass (g) & Corticosterone (pg per mg) \\
\hline Population (sample size) & Mean \pm SD (range) & Mean \pm SD (range) & Mean \pm SD (range) \\
\hline \multicolumn{4}{|l|}{ Female } \\
\hline POP1 $(n=9)$ & $41.6 \pm 5.8(35.0-49.3)$ & $4.4 \pm 2.2(2.0-7.6)$ & $0.9 \pm 0.3(0.4-1.3)$ \\
\hline POP2 $(n=5)$ & $47.5 \pm 2.2(45.7-50.7)$ & $7.2 \pm 1.0(5.8-8.1)$ & $0.9 \pm 0.5(0.5-1.6)$ \\
\hline POP3 $(\mathrm{n}=8)$ & $43.4 \pm 8.7(34.0-51.6)$ & $6.0 \pm 3.0(1.5-9.1)$ & $0.9 \pm 0.4(0.4-1.5)$ \\
\hline POP4 $(n=10)$ & $46.3 \pm 2.3(40.6-49.3)$ & $6.8 \pm 1.4(4.2-9.5)$ & $1.2 \pm 0.5(0.4-1.8)$ \\
\hline \multicolumn{4}{|l|}{ Male } \\
\hline POP1 $(\mathrm{n}=11)$ & $42.1 \pm 3.9(35.0-47.7)$ & $4.4 \pm 1.4(2.3-6.7)$ & $0.6 \pm 0.2(0.3-1.1)$ \\
\hline POP2 $(\mathrm{n}=17)$ & $39.0 \pm 5.4(35.0-47.3)$ & $3.9 \pm 1.7(2.3-7.2)$ & $1.0 \pm 0.3(0.8-1.6)$ \\
\hline POP3 $(n=10)$ & $41.8 \pm 5.5(34.3-48.3)$ & $5.4 \pm 2.4(2.1-7.7)$ & $1.1 \pm 0.6(0.4-2.4)$ \\
\hline POP4 $(n=14)$ & $46.2 \pm 2.0(41.3-50.0)$ & $6.7 \pm 1.3(3.8-9.7)$ & $1.4 \pm 0.8(0.6-3.2)$ \\
\hline
\end{tabular}

concentration as a result of capture are detectable after 30 minutes (Ricciardella et al., 2010), we assumed that baseline corticosterone measurements were not biased by manipulation in the field. The toads were then measured, weighed using a precision electronic balance, and released. Sample size per sex and population, and descriptive statistics of body size (snout-vent length), weight and baseline corticosterone concentrations are presented in Table 2.

\section{Dosing corticosterone levels}

Corticosterone in saliva samples was analysed by enzymelinked immunoassay, using protocols validated previously for amphibians (Janin et al., 2012). Each cotton ball was weighed, put in a microtube equipped with a filter to retain the cotton fibre during centrifugation, and stored at $-80^{\circ} \mathrm{C}$. Samples were reconstituted by addition of $150 \mu \mathrm{L}$ of phosphate buffer (1 M phosphate solution containing $1 \%$ bovine serum albumin, $4 \mathrm{M}$ sodium chloride, $10 \mathrm{mM}$ ethylenediaminetetraacetic acid and $0.1 \%$ sodium azide) and centrifuged. Samples were diluted and analysed in duplicate using a 96-well colometric enzyme-linked immunoassay kit (500651, Cayman Chemical Company, Ann Arbor, USA). Coloration was evaluated using a spectrometer (Absorbance Microplate Reader ELx8o8, Biotek, Winooski, USA) at $405 \mathrm{~nm}$ wavelength The concentration of corticosterone in saliva samples was calculated using a standard curve run on each plate. We estimated the corticosterone concentration in $1 \mathrm{mg}$ of saliva by dividing the measure in samples by the weight of saliva collected.

\section{Statistical analysis}

Prior to analysis all continuous variables (i.e. body size, weight and corticosterone concentration; Table 2) were zero-centred to fit a normal distribution. Body size was logtransformed to model body condition. We investigated whether body size (snout-vent length, SVL) and corticosterone level (CORT) varied between the sexes (SEX) and according to exposure to traffic (STATUS: exposure to traffic vs control situation). For that purpose we used linear mixed models, treating SVL and CORT as the dependent variables. The nominal variables SEX and STATUS and their interactive effect were introduced as explanatory terms in the fixed part of the model, and the population of origin was introduced as a random effect. To examine the influence of STATUS on body condition according to sex we performed a covariance analysis using body weight (WEIGHT) as the dependent variable and SVL as the adjustment covariate. SEX, STATUS, SVL and all their interactive effects were thus introduced as explanatory terms in the fixed part of the model, and the population of origin was introduced as a random effect. All analyses were performed using restricted maximum likelihood optimization. Firstly, we checked variance homogeneity between the two population statuses. For that purpose we specified a distinct error term for each status in the covariance structure of the mixed model and we used a likelihood ratio test to estimate the significance of variance heterogeneity. If insignificant, variance heterogeneity was then removed from the model. Normality of the residuals was examined graphically using a quantilequantile plot. The significance of each explanatory term introduced in the models was estimated, using non-sequential F statistics (Type III test) and the Kenward-Roger approximation to calculate degrees of freedom. If non-significant, interactive terms were then removed from the model. Otherwise, sliced tests were performed to investigate main effects in the presence of interactive ones. All analyses were implemented in SAS v. 9.3 (SAS Institute, Cary, USA).

\section{Results}

The maximum likelihood ratio test indicated that heterogeneity of variance in body size among populations was 
TABLE 3 Effects of gender (SEX) and population status (STATUS, exposed to intensive vehicle traffic or not) on body size in the yellowbellied toad, based on an ANOVA $F$-test type III and least-square mean evaluation for linear combinations, with degrees of freedom, and $F$, $\mathrm{t}$ and $\mathrm{P}$ values.

\begin{tabular}{llcc}
\hline Fixed effects & & & \\
\hline ANOVA $\boldsymbol{F}$-test Type III & df (residual) & & P \\
SEX & 53.4 & $\boldsymbol{F}$ & 0.121 \\
STATUS & 49.3 & 2.49 & $<0.001$ \\
SEX|STATUS & 53.4 & 14.94 & 0.144 \\
Least-squares mean evaluation & df & 2.20 & $\mathbf{P}$ \\
Females (exposed) & 29.9 & $\boldsymbol{t}$ & $<0.001$ \\
Females (control) & 24.6 & 26.8 & $<0.001$ \\
Males (exposed) & 36.8 & 68.8 & $<0.001$ \\
Males (control) & 24.3 & 38.6 & $<0.001$ \\
\hline
\end{tabular}

${ }^{*}$ Degrees of freedom associated with residual variance

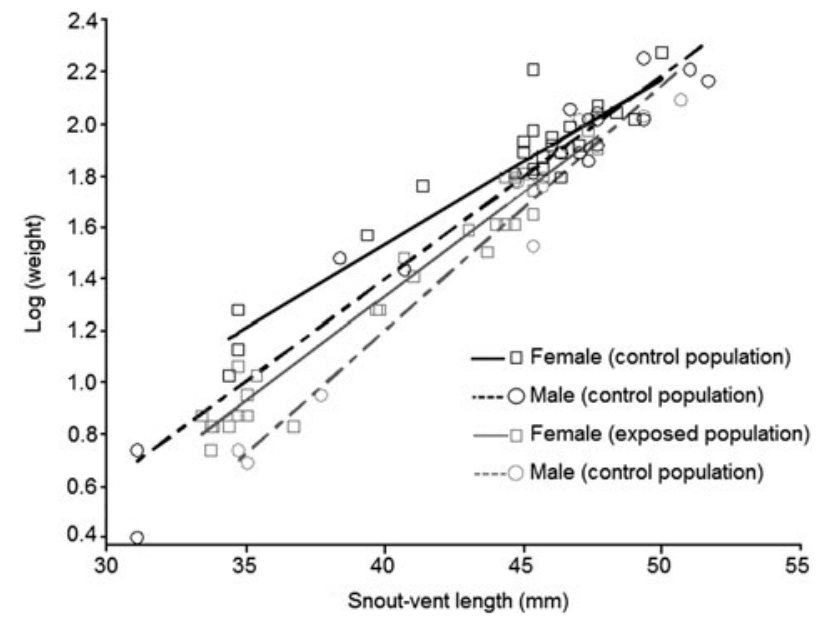

Fig. 2 Relationship between weight (log-transformed) and body size (snout-vent length) in the yellow-bellied toad, according to sex and population status.

significant $\left(\chi_{1,3}^{2}=27.53, \mathrm{P}<0.001\right)$. Body size was marginally influenced by sex $\left(F_{1,47.1}=2.49, \mathrm{P}=0.12\right.$; Table 3$)$. The interaction SEX|STATUS also had a marginal effect $\left(F_{1,47.1}=2.20\right.$, $\mathrm{P}=0.14)$. Body size varied significantly according to population status $\left(F_{1,47.1}=2.49, \mathrm{P}<0.001\right)$. Toads exposed to traffic were smaller than those in control populations (Fig. 3a).

The model outputs are in Table 4. The maximum likelihood ratio test indicated that heterogeneity of variance in body condition among populations was significant $\left(\chi_{1,3}^{2}=8.40, P=0.04\right)$. The interaction SEX|STATUS was not significant $\left(F_{1,49 \cdot 3}=0.29, \mathrm{P}=0.59\right)$. We detected two significant interactions: SVL|STATUS $\left(F_{1,53.4}=8.04\right.$, $\mathrm{P}=0.006)$ and SVL $\mid \operatorname{SEX}\left(F_{1,53.4}=8.66, \mathrm{P}=0.005\right)$. Our results show that body condition depends on sex and population status (Fig. 2). Females had better body condition than males, regardless of population status. According to the slicing procedure sex-biased body size was significant only for the two first quartiles $\left(Q_{1}=39.3 \mathrm{~mm}, Q_{2}=45.0 \mathrm{~mm}\right)$ of the size range (Table 4). Individuals exposed to intensive traffic had an inferior body condition compared to those in control populations. This difference was significant throughout the size range (Table 4).

The maximum likelihood ratio test indicated that heterogeneity of variance in corticosterone concentration among populations was significant $\left(\chi_{1,3}^{2}=8.75, \mathrm{P}=0.03\right)$. Baseline corticosterone concentration was not influenced by sex $\left(F_{1,33.2}=0.42, \quad \mathrm{P}=0.52 ;\right.$ Table 5$)$. The interaction SEX| STATUS had a marginal effect $\left(F_{1,50.1}=0.85, \mathrm{P}=0.36\right)$. Corticosterone concentration varied according to population status $\left(F_{1,31.5}=5.31, \mathrm{P}=0.02\right)$. Individuals of both sexes exposed to intensive traffic had lower corticosterone concentrations than those in control populations (Fig. 3 b).

\section{Discussion}

Our results indicate that exposure to intensive vehicle traffic results in a smaller body size in both sexes. The underlying mechanisms are potentially multiple, implicating complex relationships between the toad and its environment, possibly both before and after metamorphosis. During larval ontogeny, changes in tadpole density and/or water temperature in development sites resulting from habitat alteration caused by vehicle traffic on pathways may explain differences in body size at metamorphosis and thereafter at the adult stage (Morand et al., 1997). A reduced body size can also result from maternal effects (Dziminski \& Roberts, 2006; Wells, 2010) through a decrease in the yolk reserves allocated to eggs, which affects embryo development, larval growth and body size at metamorphosis in altered habitats. A smaller adult body size may also reflect increased mortality as a direct result of vehicle traffic (Glista et al., 2008), as shown in the common frog Rana temporaria (Augert \& Joly, 1993). In B. variegata body size plays a critical role in competition between males, affecting mating behaviour and tactics (Seidel, 1999). In females, Rafińska (1991) showed a positive correlation between clutch size and body size. Thus, intensive vehicle traffic on unpaved roads could 
TABLE 4 Effects of gender (SEX) and population status (STATUS, exposed to intensive vehicle traffic or not) on body condition (modelled as linear function between weight and body size, SVL) in the yellow-bellied toad, based on an ANOVA F-test type III and a slicing procedure for linear combinations, with degrees of freedom associated with residual variance, and $F$ and $\mathrm{P}$ values.

\begin{tabular}{|c|c|c|c|}
\hline Fixed effects & df (residual) & $\mathrm{F}$ & $\mathrm{P}$ \\
\hline \multicolumn{4}{|l|}{ ANOVA F-test type III } \\
\hline SVL & 53.4 & 838.04 & $<0.001$ \\
\hline SEX & 49.3 & 10.21 & 0.002 \\
\hline STATUS & 49.3 & 11.02 & 0.002 \\
\hline SVL|SEX & 53.4 & 8.66 & 0.005 \\
\hline SVL|STATUS & 53.4 & 8.04 & 0.006 \\
\hline SEX|STATUS & 49.3 & 0.29 & 0.594 \\
\hline SVL|SEX|STATUS & 53.4 & 0.22 & 0.644 \\
\hline \multicolumn{4}{|c|}{ Slicing procedure for linear combinations } \\
\hline SVL|STATUS Q1 = 39.3 & 46.0 & 31.84 & $<0.001$ \\
\hline SVL $\mid$ STATUS $Q 2=45.0$ & 67.8 & 22.28 & $<0.001$ \\
\hline SVL|STATUS Q3 $=46.7$ & 61.0 & 11.04 & 0.001 \\
\hline SVL|SEX Q1 = 39.3 & 42.1 & 14.74 & $<0.001$ \\
\hline SVL|SEX Q2 = 45.0 & 60.5 & 5.48 & 0.023 \\
\hline SVL|SEX Q3 = 46.7 & 56.1 & 1.58 & 0.215 \\
\hline
\end{tabular}

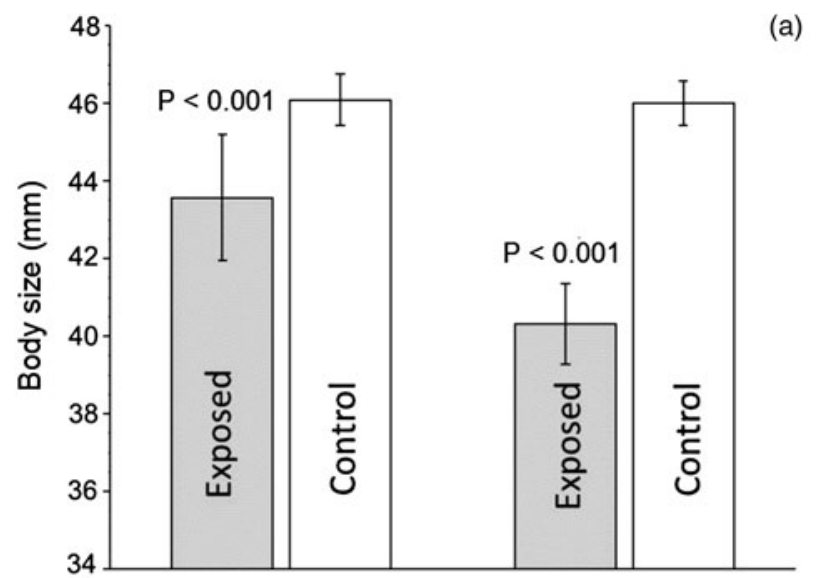

(b)

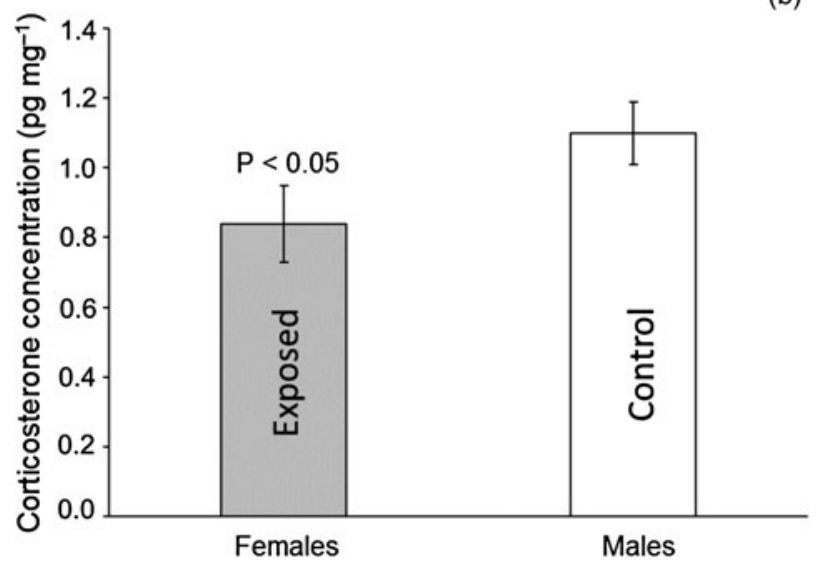

Fig. 3 Mean effect $( \pm$ SE) of intensive vehicle traffic on body size (a) and endocrine stress response (b) in the yellow-bellied toad in exposed populations compared with control populations, based on mixed linear modelling.
TABLE 5 Effects of gender (SEX) and population status (STATUS, exposed to intensive vehicle traffic or not) on corticosterone concentrations in the yellow-bellied toad, based on an ANOVA F-test type III, with degrees of freedom associated with residual variance, and $\mathrm{F}$ and $\mathrm{P}$ values.

\begin{tabular}{llll}
\hline Fixed effects & df (residual) & F & $\mathrm{P}$ \\
\hline SEX & 33.2 & 0.42 & 0.520 \\
STATUS & 61.3 & 5.61 & 0.021 \\
SEX|STATUS & 53.1 & 0.85 & 0.361 \\
\hline
\end{tabular}

influence sexual selection regimes and reproductive outputs in B. variegata populations.

Our results also show that intensive vehicle traffic results in reduced body condition in both sexes. Poor body condition in exposed populations may result from suboptimal population density triggered by reduced carrying capacities of degraded habitats; for example, alteration of terrestrial habitat can lead to food shortage and nutritional stress by reducing the availability and quality of ground-dwelling insect prey. In amphibians poor body condition usually decreases fitness by negatively influencing annual survival rates (Feder \& Burggren, 1992). Moreover, in females a decrease in body condition as a result of habitat alteration has been linked to a reduction in energy reserves (triglycerides and whole lipids), leading to a decrease in reproductive investment and low fecundity (Scott \& Fore, 1995; Homyack \& Haas, 2009). In the yellow-bellied toad, a female's annual breeding decision depends on a combination of internal factors (including energy reserves) and environmental cues (Cayuela et al., 2014). Accordingly, a reduction in energy reserves caused by exposure to vehicle traffic has a detrimental effect on female fecundity. 
We found that corticosterone production is lower in populations exposed to intensive vehicle traffic than in control populations. We cannot rule out the possibility that this result may be attributable to the low number of populations sampled and/or the absence of stress-induced measurements. Furthermore, as glucocorticoid production constitutes an immediate response to an environmental stressor, it is conceivable that the observed pattern may be the result of stress responses to one or several factors other than the intensity of vehicle traffic. We suggest that good quality habitat may favour increased sexual activity (male-male competition and female harassment by males), enhancing corticosterone production. Unlike in birds and mammals, it seems that the inhibition effects of glucocorticoids on the reproductive system, through the suppression of gonadal hormone secretion, is equivocal in amphibians (Narayan, 2013). In the cane toad Rhinella marina, for example, after stress induction, corticosterone production covaries positively with testosterone secretion when toads are sexually active, whereas an inverse relationship is reported in non-breeding toads (Narayan et al., 2012a,b). In Woodhouse's toads Bufo woodhousii there is a positive correlation between sexual activity (vocal effort) and circulating corticosterone levels although corticosterone production is not related to the production of sexual steroids (Leary et al., 2008). These examples illustrate the complexity of the relationships between the reproductive endocrine system (the hypothalamo-pituitary-gonadal axis), the stress endocrine system (the hypothalamo-pituitary-interrenal axis) and amphibian behaviour. Thus, despite the current trend for physiological conservation and the use of glucocorticoids as bio-indicators in amphibians (Narayan, 2013), the observed patterns should be considered with caution and preferentially in combination with other biological indices (e.g. morphological).

\section{Conservation recommendations}

We suggest that the intensity of vehicle traffic should be limited during the breeding season of the yellow-bellied toad (April-September). We consider two scenarios: (1) traffic does not affect economic activities directly (e.g. use of nonessential unpaved roads by individuals for leisure activity) and can be avoided during the breeding season; (2) traffic directly affects economic activities (e.g. use of essential unpaved roads for forestry or quarry activities) and cannot be avoided. In the first case we propose the exclusion of traffic from aquatic habitats and a $500 \mathrm{~m}$ diameter buffer zone around these habitats (Hartel, 2008) during the breeding season, to avoid deleterious effects on recruitment and adult survival. Traffic may be authorized during OctoberMarch. In the second case we encourage multilateral conventions between environmental protection organizations or governmental agencies for nature conservation and territorial authorities or professionals such as mining operators.
The conditional use of roads, as well as any quarry exploitation plan, should be adapted, taking into account the specificity of local situations and contexts; for example, breeding sites should be protected from traffic by creating alternative pathways, which should be stabilized and maintained using rockfill to avoid rut creation. During the nonbreeding season (October-March) the use of pathways should not be restricted to avoid the natural silting up of existing breeding sites and to ensure the creation of new ones. If this is not possible, substitute breeding sites could be created away from the pathways used for sustaining essential economic activities. These recommendations are under negotiation with the mining operator at one of the two study sites exposed to vehicle traffic. Further investigation will be required to evaluate and compare the effectiveness of these management recommendations.

\section{Acknowledgements}

This research was funded by the Société des Carrières du Bourget du Lac, whose partners Jerome Langain and Regis Chevallier have been involved in the conservation of the yellow-bellied toad for almost 10 years. Capture of toads was authorized by the Conseil Scientifique Régional du Patrimoine Naturel of Rhône-Alpes (REMIPP-13-BRM229-RD).

\section{References}

Altwegg, R. \& Reyer, H.U. (2003) Patterns of natural selection on size at metamorphosis in water frogs. Evolution, 57, 872-882.

Augert, D. \& Joly, P. (1993) Plasticity of age at maturity between two neighbouring populations of the common frog (Rana temporaria L.). Canadian Journal of Zoology, 71, 26-33.

Barandun, J. \& Reyer, H.U. (1998) Reproductive ecology of Bombina variegata: habitat use. Copeia, 2, 497-500.

Blaustein, A.R., Gervasi, S.S., Johnson, P.T., Hoverman, J.T., Belden, L.K., Bradley, P.W. \& Xie, G.Y. (2012) Ecophysiology meets conservation: understanding the role of disease in amphibian population declines. Philosophical Transactions of the Royal Society $B, 367,1688-1707$.

Canessa, S., Oneto, F., Ottonello, D., Arillo, A. \& Salvidio, S. (2013) Land abandonment may reduce disturbance and affect the breeding sites of an Endangered amphibian in northern Italy. Oryx, $47,280-287$.

Carey, C. \& Alexander, M.A. (2003) Climate change and amphibian declines: is there a link? Diversity and Distributions, 9, 111-121.

Cayuela, H., Besnard, A., Bonnaire, E., Perret, H., Rivoalen, J., Miaud, C. \& Joly, P. (2014) To breed or not to breed: past reproductive status and environmental cues drive current breeding decisions in a long-lived amphibian. Oecologia, 176, 107-116.

Cayuela, H., Besnard, A. \& Joly, P. (2013) Multi-event models reveal the absence of interaction between an invasive frog and a native endangered amphibian. Biological Invasions, 15, 2001-2012.

Cayuela, H., Cheylan, M. \& Joly, P. (2011) The best of a harsh lot in a specialized species: breeding habitat use by the yellow-bellied toad (Bombina variegata) on rocky riverbanks. Amphibia-Reptilia, 32, 533-539. 
Cayuela, H., Lambrey, J., Vacher, J.P. \& Miaud, C. (2015) Highlighting the effects of land-use change on a threatened amphibian in a human-dominated landscape. Population Ecology, $57,433-443$.

Cushman, S.A. (2006) Effects of habitat loss and fragmentation on amphibians: a review and prospectus. Biological Conservation, 128, 231-240.

DenoëL, M. \& Poncin, P. (2001) The effect of food on growth and metamorphosis of paedomorphs in Triturus alpestris apuanus. Archiv Für Hydrobiologie, 152, 661-670.

Dziminski, M.A. \& Roberts, J.D. (2006) Fitness consequences of variable maternal provisioning in quacking frogs (Crinia georgiana). Journal of Evolutionary Biology, 19, 144-155.

Feder, M.E. \& Burggren, W.W. (eds) (1992) Environmental Physiology of the Amphibians. University of Chicago Press, Chicago, USA.

Glista, D.J., DeVault, T.L. \& DeWoody, J.A. (2008) Vertebrate road mortality predominantly impacts amphibians. Herpetological Conservation and Biology, 3, 77-87.

Hartel, T. (2008) Movement activity in a Bombina variegata population from a deciduous forested landscape. North-Western Journal of Zoology, 4, 79-9o.

Hill, R.W., Wyse, G.A. \& Anderson, M. (2008) Animal Physiology. Sinauer Associates, New York, USA.

Hомуаск, J.A. \& HaAs, C.A. (2009) Long-term effects of experimental forest harvesting on abundance and reproductive demography of terrestrial salamanders. Biological Conservation, 142, 110-121.

IUCN (2015) The IUCN Red List of Threatened Species v. 2015.1. Http:// www.iucnredlist.org [accessed 5 August 2015].

Janin, A., Léna, J.P., Deblois, S. \& Joly, P. (2012) Use of stresshormone levels and habitat selection to assess functional connectivity of a landscape for an amphibian. Conservation Biology, 26, 923-931.

Janin, A., LÉnA, J.P. \& Joly, P. (2011) Beyond occurrence: body condition and stress hormone as integrative indicators of habitat availability and fragmentation in the common toad. Biological Conservation, 144, 1008-1016.

Kats, L.B. \& Ferrer, R.P. (2003) Alien predators and amphibian declines: review of two decades of science and the transition to conservation. Diversity and Distributions, 9, 99-110.

Kopecky, O., Vojar, J. \& Denoël, M. (2010) Movements of Alpine newts (Mesotriton alpestris) between small aquatic habitats (ruts) during the breeding season. Amphibia-Reptilia, 31, 109-116.

Kuzmin, S., Denoël, M., Anthony, B., Andreone, F., Schmidt, B., Ogrodowczy K, A. et al. (2009) Bombina variegata. In The IUCN Red List of Threatened Species v. 2015.2. Http://www.iucnredlist.org [accessed 3 August 2015].

Leary, C.J., Garcia, A.M., Knapp, R. \& Hawkins, D.L. (2008) Relationships among steroid hormone levels, vocal effort and body condition in an explosive-breeding toad. Animal Behaviour, $76,175-185$.

Lescure, J., Pichenot, J. \& Cochard, P.O. (2011) Régression de Bombina variegata (Linné, 1758) en France par l'analyse de sa répartition passée et présente. Bulletin de la Société Herpétologique de France, 137, 5-41.
McEwen, B.S. \& Wingfield, J.C. (2003) The concept of allostasis in biology and biomedicine. Hormones and Behavior, $43,2-15$.

Moore, I.T. \& Jessop, T.S. (2003) Stress, reproduction, and adrenocortical modulation in amphibians and reptiles. Hormones and Behavior, 43, 39-47.

Morand, A., Joly, P. \& Grolet, O. (1997) Phenotypic variation in metamorphosis in five anuran species along a gradient of stream influence. Comptes Rendus de l'Académie des Sciences III, 320, 645-652.

Narayan, E.J. (2013) Non-invasive reproductive and stress endocrinology in amphibian conservation physiology. Conservation Physiology, 1, 1-16.

Narayan, E.J., Hero, J.M. \& Cockrem, J.F. (2012a) Inverse urinary corticosterone and testosterone metabolite responses to different durations of restraint in the cane toad (Rhinella marina). General and Comparative Endocrinology, 179, 345-349.

Narayan, E.J., Molinia, F.C., Cockrem, J.F. \& Hero, J.M. (2012b) Changes in urinary testosterone and corticosterone metabolites during short-term confinement with repeated handling in wild male cane toads (Rhinella marina). Australian Journal of Zoology, 59, 264-269.

Rafińska, A. (1991) Reproductive biology of the fire-bellied toads, Bombina bombina and B. variegata (Anura: Discoglossidae): egg size, clutch size and larval period length differences. Biological Journal of the Linnean Society, 43, 197-210.

Ricciardella, L.F., Bliley, J.M., Feth, C.C. \& Woodley, S.K. (2010) Acute stressors increase plasma corticosterone and decrease locomotor activity in a terrestrial salamander (Desmognathus ochrophaeus). Physiology \& Behavior, 101, 81-86.

ScotT, D.E. \& Fore, M.R. (1995) The effect of food limitation on lipid levels, growth, and reproduction in the marbled salamander, Ambystoma opacum. Herpetologica, 51, 462-471.

SEIDEL, B. (1999) Water-wave communication between territorial male Bombina variegata. Journal of Herpetology, 33, 457-462.

Todd, B.D. \& Rothermel, B.B. (2006) Assessing quality of clearcut habitats for amphibians: effects on abundances versus vital rates in the southern toad (Bufo terrestris). Biological Conservation, 133, 178-185.

Wells, K.D. (2010) The Ecology and Behavior of Amphibians. University of Chicago Press, Chicago, USA.

\section{Biographical sketches}

Hugo Cayuela conducts research on evolution and conservation biology, and is particularly interested in amphibians. LUDIVINE QUAY works on amphibian and reptile conservation. Adeline DUMET is a laboratory technician interested in ecophysiological and genetic analyses. JEAN-PAUL LÉNA's research interests include dispersal ecology and evolution, sexual selection and population dynamics. Cla UdE Miaud's research interests lie in amphibian ecology and conservation. VINCENT RIVIERE is a conservationist specializing in ecological restoration and the ecological management of industrial projects. 